NOTAS 



\title{
LA INDEPENDENCIA Y EL GOBIERNO DE LOS JUECES. UN DEBATE CONSTITUCIONAL ${ }^{1}$
}

\author{
PABLO LUCAS MURILLO DE LA CUEVA \\ Magistrado del Tribunal Supremo \\ Catedrático de Derecho Constitucional \\ Universidad de Córdoba
}

\section{SUMARIO}

I. El contexto. II. Los términos de la polémica. III. Las novedades legislativas del siglo XXI. IV. Apuntes de la realidad. V. Elementos de contraste. VI. La independencia y la sumisión a la Ley de los jueces españoles. VII. La independencia judicial y la opinión pública. VIII. Hacia unas conclusiones sobre el gobierno del Poder Judicial. IX. Consideración final.

\section{EL CONTEXTO}

Cerca de cumplirse los cuarenta años de vigencia de la Constitución de 1978 son cada día más abundantes las opiniones que cuestionan la adecuación a la realidad de muchas de sus normas y defienden la necesidad de ajustarlas a las condiciones de vida de la sociedad del siglo XXI y a las características del Estado construido a partir de sus disposiciones ${ }^{2}$. Al natural efecto que produce el transcurso del tiempo, dos factores de reciente aparición han hecho que cobren últimamente más fuerza.

De un lado, las consecuencias traídas por la crisis económica han acentuado y extendido el reproche a los poderes públicos de no responder a los anhelos y preocupaciones de los ciudadanos y la impresión de que el texto fundamental no es suficiente para satisfacerlos. Y, del otro, el desafío que supone el secesionismo

1 El siguiente texto, al que se le han añadido algunas notas, forma parte del discurso de recepción como académico de número de la Real Academia de Ciencias Morales y Políticas leído el 23 de mayo de 2017. La versión íntegra está en http://www.racmyp.es/R/racmyp//docs/discursos/D92.pdf.

2 Véase García Roca, J (editor); Pautas para una reforma constitucional. Informe para el debate. Instituto de Derecho Parlamentario de la Universidad Complutense/Thomson Reuters Aranzadi, Cizur Menor, 2014. 
catalán y las posibles respuestas que desde el respeto a la Constitución es posible darle. Ambas causas han contribuido a situar la cuestión de su reforma en el primer plano de la actualidad e, incluso, le han dado un aire de urgencia, cuando no de dramatismo que no ha tenido hasta ahora.

Hago esta precisión porque no es algo nuevo discutir sobre la reforma de la Constitución. Propuestas para mejorarla las ha habido casi desde su entrada en vigor.

Sin embargo, hasta muy recientemente no han aparecido entre los aspectos en que se han sugerido reformas constitucionales los relativos al Poder Judicial.

Resuelta sin particulares dificultades su regulación en las Cortes que hicieron la Constitución ${ }^{3}$, después ha habido controversias particulares pero, con excepción de la forma de componer el Consejo General del Poder Judicial a partir de 1985, no se ha debatido sobre el tratamiento constitucional del Poder Judicial y mucho menos encontramos propuestas de reformarlo pues las avanzadas se limitaron a reclamar la modificacion de su Ley Orgánica para volver al régimen de elección de los vocales judiciales establecido en 1980.

En ese mismo nivel legislativo se situaron las iniciativas que al hilo de la elaboración de los estatutos de Cataluña y de Andalucía buscaron adecuar el Poder Judicial a la realidad del Estado autonómico y propusieron para ello potenciar los Tribunales Superiores de Justicia, reservar al Tribunal Supremo la unificación de doctrina y flanquear al Consejo General del Poder Judicial con unos consejos judiciales autonómicos que serían órganos desconcentrados suyos $^{4}$. El Tribunal Constitucional fijó en su sentencia 31/2010 los límites en que puede desenvolverse el legislador estatutario y declaró inconstitucionales los preceptos del estatuto catalán que afrontaban esos extremos. No obstante, esa preocupacion por ajustar el Poder Judicial a la organización territorial tiene unas características propias en las que la cuestión de la independencia

3 Así resulta de cuanto exponen Alzaga Villaamil, O; Comentario Sistemático a la Constitución Española de 1978. Ediciones El Foro, Madrid 1978, págs., 707 y sigs, y ahora, en su $2^{\text {a }}$ edición, editada por Marcial Pons, Madrid, 2017, págs., 541 y sigs. y Díez-Picazo Giménez, L. Ma en sus obras Régimen constitucional del Poder Judicial. Civitas, Madrid, 1991, y La Jurisdicción en España. Un ensayo de valoración constitucional, Instituto de Estudios Económicos, Madrid, 1994. Sobre el punto de partida de los trabajos constituyentes, véase Ollero Tassara, A; «Poder Judicial y transición democrática en España», en Sociología y Psicología Jurídicas. Anuario de 1982. Ilustre Colegio de Abogados de Barcelona, Barcelona, 1982, págs., 6 y sigs. Andrés Ibáñez, P; y Movilla Álvarez, C; El Poder Judicial. Tecnos, Madrid, 1986, ofrecieron una primera explicación completa del ordenamiento que descansa en el Título VI de la Constitución.

4 Sobre el particular, véanse: Gerpe Landín, M (coord.), La posición del Tribunal Supremo en el Estado autonómico. Institut d'Estudis Autonomics, Barcelona, 2008; Id., Posición y funciones de los Tribunales Superiores de Justicia. Institut d'Estudis Autonomics, Barcelona, 2009; Gerpe Landín, M; y Cabellos Espiérrez, M. A (coord.), Poder Judicial y modelo de Estado. Atelier, Barcelona, 2013; id. El gobierno del Poder Judicial en el Estado autonómico. Evolución y perspectivas de reforma. Marcial Pons, Madrid 2013; PAREJA, M.A; El Poder Judicial y las Comunidades Autónomas. Especial referencia a Andalucía. Diputación de Córdoba, Córdoba, 2015. También, las observaciones que expuse en mi trabajo «El Poder Judicial en el Estado Autonómico», Teoría y realidad constitucional, $\mathrm{n}^{\circ}$ 5/2001, págs. 89 y sigs. 
judicial no aparece directamente concernida en los aspectos en que se está discutiendo hoy.

En estos últimos años, en el ambiente político originado por la crisis han aflorado expresiones sumamente críticas con prácticamente todas las instituciones constitucionales.

El Poder Judicial no podía ser —y no lo ha sido— una excepción.

La preocupación por la independencia de los jueces, la denuncia de la politización de la Justicia, junto a la polémica sobre la formación del Consejo, han pasado a ocupar un lugar preferente en el debate público mientras que en el plano político se avanzan planes para reformarlo o, incluso, para suprimirlo5.

\section{LOS TÉRMINOS DE LA POLÉMICA}

A fin de situar el problema conviene repasar los datos normativos.

La Constitución ha confiado el Poder Judicial a los juzgados y tribunales y, en particular, a los jueces que los sirven. Además, quiere que sean independientes, inamovibles, responsables y únicamente sometidos al imperio de la Ley pues sólo así podrán tutelar efectivamente los derechos e intereses de todos y controlar la legalidad de la actuación de los poderes públicos, que es su cometido.

Ha creado, igualmente, el Consejo General del Poder Judicial al que ha encargado lo que llamamos gobierno de los jueces. Consiste en nombrarlos, ascenderlos, inspeccionar su trabajo y aplicarles el régimen disciplinario ${ }^{6}$.

El Consejo recibe esas atribuciones para detraerlas del Poder Ejecutivo a fin de salvaguardar mejor la independencia judicial. Su idoneidad para lograrlo viene de su autonomía, pues no está subordinado a ningún otro órgano.

5 Bastará con recordar las informaciones publicadas sobre las propuestas del partido político Ciudadanos de suprimir el Consejo General del Poder Judicial y encomendar sus competencias sobre nombramientos al Presidente del Tribunal Supremo, elegido por el Congreso, auxiliado por dos adjuntos elegidos por los jueces: [http:// politica.elpais.com/política /2015/11/07/actualidad/1446884889_172099.html y http://www.elmundo. es/2015/11/07/563 dd614e2704ee16c8b45ec.html]. Más tarde ese mismo partido, en el curso de las negociaciones para la investidura del Presidente del Gobierno, defendió la vuelta a la elección de los vocales de procedencia judicial por los jueces [http://politica.elpais.com/politica/2016/02/18/actualidad /1455816623_255108.html y http://politica.elpais.com/politica/2016/08/26/actualidad/14722 34479_885933.html]. Y así se recogió en la medida 102 de las 150 entonces pactadas [http://www.rtve.es/ contenidos/documentos/documento_pp-cs.pdf]. Por su parte, las asociaciones judiciales (Asociación Profesional de la Magistratura, la Asociación Francisco de Vitoria, Jueces para la Democracia y el Foro Judicial Independiente), hicieron pública el 30 de agosto de 2016 una declaración expresando su satisfacción por el Pacto de Investidura alcanzado entre el Partido Popular y Ciudadanos, en primer lugar, porque contempla la elección de los vocales de procedencia judicial por los jueces.

6 Véanse, entre otros, los trabajos específicos de Terol Becerra, M; El Consejo General del Poder Judicial, Centro de Estudios Constitucionales, Madrid, 1990, Gerpe Landín, M; «La composición del Consejo General del Poder Judicial», Revista del Centro de Estudios Constitucionales nº 9/1991, págs. 145 y sigs; y Ballester Cardell, M; El Consejo General del Poder Judicial. Su función constitucional y legal. Premio Rafael Martínez Emperador 2006. Consejo General del Poder Judicial, Madrid, 2007. 
Presidido por el Presidente del Tribunal Supremo, al que elige el propio Consejo, lo forman veinte vocales con mandato de cinco años. Doce han de ser nombrados entre jueces en activo de todas las categorías por el procedimiento que la Ley Orgánica del Poder Judicial establezca y ocho designados, cuatro por el Congreso y cuatro por el Senado, por mayoría de tres quintos, entre abogados y otros juristas de reconocida competencia con más de quince años de ejercicio profesional.

Prevista por el legislador en 1980 la elección de los doce vocales judiciales por los propios jueces, en 1985 se atribuyó su designación a las Cortes Generales, por mayoría de tres quintos.

Contra este cambio ${ }^{7}$ se alzó el primer Consejo, que promovió tres conflictos constitucionales y, después, el Grupo Popular cuyos parlamentarios interpusieron un recurso de inconstitucionalidad contra la Ley Orgánica del Poder Judicial que dispuso ese cambio.

El Tribunal Constitucional con su sentencia 45/1986 rechazó los conflictos dejando claro que el Consejo no es un órgano representativo de la carrera judicial, ni del Poder Judicial y que no ejerce el autogobierno de los jueces.

El recurso de inconstitucionalidad veía en la atribución a las Cortes de la designación también de los doce vocales jueces el cauce para que penetrara la política en el ámbito judicial pues partía de la idea de que los designados por las cámaras son transmisores de los criterios políticos de los grupos parlamentarios que les proponen, mientras que la elección por los jueces no comporta ese efecto para los elegidos.

El Tribunal Constitucional, ahora en su sentencia 108/1986, se hizo eco de esta preocupación después de haber concluido que la Constitución no obliga a que sean los jueces los que elijan a esos doce vocales y que queda a la decisión del legislador establecer la forma de hacerlo siendo así tan constitucional la dispuesta en 1980 como la preferida en 1985, todavía en vigor hoy.

No obstante, hizo dos advertencias sobre los riesgos que acechan a la designación de los vocales. De un lado, el de que, si se deja la elección a los jueces, «el procedimiento electoral traspase al seno de la Carrera Judicial las divisiones ideológicas existentes en la sociedad «. De otro, refiriéndose a la designación parlamentaria, el de que las Cámaras a la hora de efectuar sus propuestas «distribuyan los puestos a cubrir entre los distintos partidos, en proporción a la fuerza

7 La gravedad del problema que podía originar, como finalmente terminó sucediendo, se percibió muy pronto. Eso explica la iniciativa que relata Javier Delgado Barrio, «La elección del gobierno de los jueces», en El Mundo, de 18 de noviembre de 2014. Antonio Pedrol Rius, a la sazón decano del Colegio de Abogados de Madrid y en su día senador constituyente por designación real, transmitió al entonces Presidente del Tribunal Supremo y del Consejo General del Poder Judicial, Federico Carlos Sáinz de Robles, que si el Consejo desistía de los conflictos, el legislador pospondría su renovación por dos años. Javier Delgado Barrio, vocal del aquél Consejo y más tarde Presidente del Tribunal Supremo, señala también los términos rotundos en que Federico Carlos Sáinz de Robles rechazó la propuesta. 
parlamentaria de éstos». «La lógica del Estado de partidos —añadió- empuja a actuaciones de este género, pero esa misma lógica obliga a mantener al margen de la lucha de partidos ciertos ámbitos de poder y entre ellos, y señaladamente, el Poder Judicial».

Asociar indefectiblemente la intervención parlamentaria en la formación del Consejo a esa lógica del Estado de partidos, implica aceptar que la propia Constitución ha querido que sí presida la designación de los otros ocho vocales ya que encomienda al Congreso de los Diputados y al Senado designar a cuatro cada uno. Establecer la relación cuasi necesaria entre designación parlamentaria y partidismo de los vocales, supone aceptar la que sería su contraria: la relación entre elección por los jueces y apartidismo de los vocales. Aún más, sugiere la contraposición entre política y técnica.

No creo necesario, recordar ahora los presupuestos e implicaciones de esas asociaciones.

Los seis Consejos que se han sucedido desde 1985, ya con todos sus vocales elegidos por las Cortes, han conocido, es verdad, confrontaciones con las mismas líneas divisorias que las establecidas en las cámaras legislativas. No creo, sin embargo, que este hecho signifique que, aún conforme con la Constitución, fuera equivocada la opción del legislador.

Hay motivos para pensar que no se hubiera evitado la polarización política del Consejo.

De un lado, la referencia ofrecida por la experiencia italiana: un Consiglio Superiore della Magistratura formado mayoritariamente por jueces elegidos por sus pares, ha protagonizado episodios no muy diferentes a los que se han podido contemplar entre nosotros ${ }^{8}$. Por otro lado, las posiciones de dos de las asociaciones judiciales guardan una clara cercanía con las de varias fuerzas políticas. No es ningún secreto que la Asociación Profesional de la Magistratura ha tenido numerosos puntos de coincidencia con el Partido Popular. Tampoco se desconoce que Jueces para la Democracia los ha tenido, principalmente, con el Partido Socialista Obrero Español pero, también, con Izquierda Unida.

La dimensión política del Consejo es, por otra parte, inevitable. La posee como la poseen todos los órganos constitucionales. Política es la solución que en cada caso se adopte sobre cómo y por quién han de ser nombrados los jueces y sobre cómo y por quién se les ha de exigir la responsabilidad que les corresponde y, en general, sobre cómo y por quién se ha de administrar su estatuto jurídico.

Destacarlo desde la defensa de la atribución a las Cortes Generales de la designación de los vocales, no significa propugnar la aplicación de criterios

8 Según la autorizada opinión de GuArnieri, C; La giustizia in Italia. Il Mulino, Bolonia, 2012, pág. 112: «Purtroppo, il Csm oggi appare ricettivo sopratutto nei confronti delle correnti organizzate e dei partiti politici che di fatto ne determinano la composizione». 
sectarios, partidistas en el peor sentido de la palabra, a la hora de escogerlos. Después volveré sobre ello.

\section{LAS NOVEDADES LEGISLATIVAS DEL SIGLO XXI}

Hubo un momento en que pareció pacificarse el conflicto surgido en 1985.

Fue cuando se alcanzó el Pacto de Estado para la reforma de la Justicia y se modificó en 2001 la Ley Orgánica para combinar la decisión parlamentaria con la participación de los jueces y de sus asociaciones en la designacion de los doce vocales de procedencia judicial.

Se trató de un espejismo, entre otras razones porque después de una apreciable movilizacion de muchos jueces, solamente fueron designados dos de los candidatos avalados por sus compañeros y no los que más avales recibieron. En las renovaciones de 2008 y de 2013, aunque para esta última ocasion se introdujeron modificaciones en el modo de proponer y avalar candidatos por parte de los jueces y sus asociaciones, no ha sido muy diferente el resultado?.

A partir de 2004, el Consejo formado en 2001 adoptó iniciativas que se vieron como una suerte de oposición a la orientación política del nuevo Gobierno. Y fue cuestionado, por unilateral, el criterio con que efectuaba los nombramientos discrecionales, es decir los de magistrados del Tribunal Supremo y los de presidentes de las Salas y Tribunales.

Por eso, en ese mismo año se reformó nuevamente la Ley Orgánica para exigir una mayoría cualificada de catorce sobre veintiún miembros para efectuar esos nombramientos. La consecuencia principal fue la de que el necesario acuerdo entre la mayoría y las minorías del Consejo se tradujo en nombramientos en algunos de los cuales se vió, no tanto el respeto a los principios de mérito y capacidad, cuanto las preferencias de las dos asociaciones profesionales más representadas en él en detrimento de las restantes y de los jueces no asociados. Hasta tal punto se percibió así que fueron objeto de recurso. Las impugnaciones prosiguieron con los nombramientos del Consejo formado en 2008 mientras que con los del actual se han reducido notablemente.

La Ley Orgánica 4/2013, de 28 de junio, a diferencia de las anteriores, ha supuesto un cambio profundo en las reglas de formación, organización y funcionamiento del Consejo. Entre las novedades, señalaré ahora las siguientes.

Para afrontar situaciones de bloqueo en la designación parlamentaria de los vocales se ha previsto que pueda constituirse con los que siguen en funciones y con los de nuevo nombramiento cuando sólo una de las cámaras cumpla en plazo su obligación de elegirlos al cabo de los cinco años de mandato.

9 Sobre la peripecia del Consejo General del Poder Judicial hasta 2008, es fundamental el libro de ÍÑ̃GUez HernándeZ, D; El fracaso del autogobierno judicial. Thomson/Civitas, Madrid, 2008. 
Por otro lado, se ha establecido un distinto régimen de dedicación de los vocales. Completa la de los miembros de la Comisión Permanente, mientras que los demás continuarán con sus actividades y solamente deberán asistir a las reuniones del Pleno y de las Comisiones a que pertenezcan. Paralelamente, el funcionamiento ordinario se pone en manos de la Comisión Permanente y, si bien se reservan las decisiones principales al Pleno, se le impide avocar los asuntos atribuidos a la Comisión Permanente.

Se han cambiado, también, las reglas sobre el quorum de constitución, antes de 14 miembros ahora de 11 sobre veintiuno, y sobre la mayoría necesaria para decidir. Salvo en los casos en que se exija una distinta, valdrá la simple de los presentes. La consecuencia es que los nombramientos discrecionales, que antes requerían un mínimo de catorce votos se deciden a favor de quien reciba más en un Pleno que puede funcionar con once miembros.

Las principales novedades de 2013 fueron objeto de un recurso de inconstitucionalidad de parlamentarios del Grupo Socialista que ha sido desestimado por la sentencia 191/2016 del Tribunal Constitucional.

Ahora bien, su juicio es incompleto. Según explica, debido a las deficiencias de la demanda, no entra en el examen de algunos de los extremos cuestionados y, particularmente, del reproche de que la diferente dedicación de los vocales les priva de funciones, poderes y garantías. Esta es, en mi opinión, la principal objeción que se puede hacer a la reforma de 2013 desde la perspectiva del artículo 122 de la Constitución pues ese distinto régimen rompe la unidad de estatuto de los vocales y divide de hecho y de Derecho el Consejo en dos órganos.

\section{APUNTES DE LA REALIDAD}

Conviene traer ahora a colación algunos datos de la realidad.

Desde 2001 se ha ido fraguando en la carrera judicial una compleja situación acompañada fuera de ella por una variedad de propuestas e iniciativas antes desconocidas.

En vísperas de las elecciones generales del 20 de diciembre de 2015 se alcanzó un hasta ahora insólito acuerdo de las cuatro asociaciones judiciales para propugnar la elección por los jueces de los doce vocales de procedencia judicial. Acuerdo reiterado el 1 de julio de 2016. Le había precedido el 8 de enero de 2014 una no menos insólita denuncia ante la ONU de la falta de independencia judicial en España por parte de la Plataforma Cívica por la Independencia Judicial ${ }^{10}$, asociación de juristas a su vez, relacionada con el anterior Manifiesto de la Plataforma por la Despolitización y la Independencia Judicial

10 Se encuentra en http://pcij.es/texto-denuncia-ante-la-onu/. 
hecho público en enero de 2010 y apoyado por numerosos jueces ${ }^{11}$. Y este mismo 2017 Jueces para la Democracia junto a Rights International Spain ha denunciado, también ante la ONU, esa falta de independencia ${ }^{12}$.

Destacaré que el Manifiesto, las denuncias y el acuerdo asociativo comparten la idea de que la designación por las Cortes de los doce vocales de procedencia judicial conduce a la intromisión de la política partidista en el Poder Judicial y merma su independencia. Además, se quejan de la falta de medios, de jueces, de inversión presupuestaria y de la creciente injerencia del Poder ejecutivo en la Administración de Justicia y de las condiciones de trabajo y retributivas. Consideran, igualmente, que el Consejo no se preocupa de estos problemas y está más atento a complacer a las instancias políticas y mediáticas que a defender a los jueces. Por eso, reclaman que sean estos los que elijan a los vocales judiciales y la adopción de las medidas precisas para corregir ese estado de cosas.

Por otro lado, en 2008 se produjo el llamado «Movimiento 8 de octubre». Una airada reacción de los jueces frente a la falta de respuesta por el Ministerio de Justicia a sus reivindicaciones profesionales y al insuficiente apoyo del Consejo, catalizada por la actuación disciplinaria contra un magistrado sevillano. El extendido descontento hizo que muchos siguieran las huelgas del 18 de febrero y del 8 de octubre de 2009. Acontecimientos llamativos ${ }^{13}$, no en vano sucedían por primera vez, plantearon la cuestión —no pacífica- de si los jueces tienen o no derecho a la huelga, parecieron imponer la respuesta afirmativa y lograron un importante seguimiento. Todavía el 20 de febrero de 2013 se convocó otra huelga, esta vez en protesta por las medidas adoptadas en materia de sustituciones, permisos y retribuciones, junto a la reivindicación de la elección por los jueces de los vocales de procedencia judicial.

La forma en que se decidió e hizo público en septiembre de 2008 quien sería Presidente del Tribunal Supremo ${ }^{14}$ y la manera en que tuvo lugar su renuncia en junio de $2012^{15}$ así como la impugnación de la elección de los vocales del Consejo y del Presidente del Tribunal Supremo en $2013^{16}$ añadieron nuevos ingredientes

11 Véase el Manifiesto hecho público el 13 de enero de 2010 en http://estaticos.elmundo.es/documentos/2010/03/06/manifiestojueces.pdf.

12 El texto de la comunicación enviada al relator especial de las Naciones Unidas para la independencia de los magistrados y abogados, Diego García Sayán, se puede ver en: http://rightsinternationalspain.org/ uploads/publicacion/82f6c32cd8d04bdb3a95e3e705de2d3cf693e211.pdf.

13 De ellos se ocupó Nieto, A; El malestar de los jueces y el modelo judicial. Editorial Trotta. Fundación Alfonso Martín Escudero, Madrid, 2010, págs.. 33 y sigs.

14 Cfr. http://www.lavanguardia.com/politica/20080922/53544647489/zapatero-proponea-carlos-divar-como-presidente-del-cgpj-y-del-tribunal-supremo.html y, también, http://elpais.com/diario/2008/09/28/ espana/1222552805_850215.html.

15 Aceptada por el Real Decreto 1034/2012, de 29 de junio.

16 Los recursos $n^{\circ} 501 / 2013$ y $71 / 2014$ contra la elección de los vocales fueron inadmitidos por los autos de la Sección Primera de la Sala Tercera del Tribunal Supremo de 28 de abril y 27 de junio de 2014 y la sentencia de esa misma Sección de 16 de diciembre de 2014 desestimó la impugnación de la elección del Presidente del Tribunal Supremo. 
a un panorama ya suficientemente complicado y contribuyeron a proyectar una imagen negativa del Consejo.

La aprobación de los Principios de Ética Judicial ${ }^{17}$ y las medidas de austeridad, transparencia y buen gobierno ${ }^{18}$ que ha emprendido el actual Consejo, apenas han conseguido paliar la impresión de que es un órgano políticamente dependiente, dividido en términos partidistas, que no resuelve los problemas reales de los jueces.

Creo que esta imagen, favorecida por la forma en que se han conducido los Consejos en ocasiones, responde principalmente a causas que le son ajenas.

De un lado, están los problemas derivados de las insuficiencias estructurales: carecemos de los jueces ${ }^{19}$ y del personal al servicio de la Administración de Justicia necesarios. Tampoco contamos con los medios precisos y la organización sigue sin ser eficiente. Es verdad que los juzgados y tribunales están sobrecargados de asuntos y que el nivel de exigencia para hacerles frente es muy elevado. Por tanto, las condiciones en que los jueces desenvuelven su función no son las más favorables y esto facilita la difusión de un ambiente crítico aunque el Consejo no sea el responsable de esas insuficiencias y deficiencias pues es radicalmente verdad en nuestro caso lo que Alexander Hamilton decía al presentar al Judicial como el poder menos peligroso, the least dangerous branch: no dispone de la fuerza ni del dinero y depende del Ejecutivo para hacer que se cumplan sus sentencias ${ }^{20}$.

Es también innegable que el poder político, como se ha visto, se ha conducido a veces de manera escasamente respetuosa con la autonomía que ha de reconocerse al Consejo, y esto ha contribuido a cimentar esa imagen negativa.

Pienso, además, que muchas de las opiniones expresadas sobre él no tienen presente el gran calado político de su cometido.

$\mathrm{Y}$, precisamente, porque decidir quién debe elegir a los vocales judiciales, que son quienes, a su vez, junto a los otros escogidos entre juristas, seleccionan, promocionan, inspeccionan y sancionan a los jueces, tiene una profunda dimensión

17 Se puede consultar en www.poderjudicial.es. Además de los principios, el documento contempla la elección de una Comisión de Ética Judicial compuesta por siete miembros, seis pertenecientes a la carrera judicial y uno al mundo académico. Los primeros a elegir por los jueces en un proceso electoral que ha de convocar el Consejo. El último a elegir por los miembros judiciales. La Comisión elegirá a su presidente. El mandato es de cuatro años y las funciones son esencialmente consultivas e informativas sin que pueda inmiscuirse en la determinación de la responsabilidad civil o penal de los jueces ni su actividad servir de referencia o complemento de actuaciones dirigidas a exigir responsabilidad civil, penal o disciplinaria salvo en beneficio del interesado.

18 En febrero de 2017 se ha hecho público el Portal de Transparencia del Tribunal Supremo. Cfr. https://www3.poderjudicial.es/cgpj/es/Poder-Judicial/Tribunal-Supremo/Portal-de-Transparencia/.

19 Estamos muy por debajo de la media europea. La Comisión Europea para la Eficiencia de la Justicia, del Consejo de Europa, cifra, con información de 2014, en 18,06 la media europea de jueces profesionales por 100.000 habitantes, mientras que la relación en España era de 11,5/100.000 [https://public.tableau.com/shared/364DJG7ZT?:display_count=yes\&:showVizHome=no]. Según los últimos datos ofrecidos por el Consejo General del Poder Judicial [La justicia dato a dato. Año 2016], a 1 de enero de 2016 eran 5.692 los jueces y magistrados españoles de manera que no cambia la situación sino que aumenta el desfase dado que a 1 de enero de 2015 eran 5.847 [La justicia dato a dato. Año 2015].

20 The Federalist, $\mathrm{n}^{\circ} 78,14$ de junio de 1788. 
política, por eso, ha pervivido tantos años la polémica y, también, por tal razón, no ha sido posible encontrarle una solución que desactive un potente factor de deslegitimación que opera sobre el órgano de gobierno del Poder Judicial y por extensión sobre el conjunto del Poder Judicial.

\section{ELEMENTOS DE CONTRASTE}

En el Consejo de Europa y en la jurisprudencia del Tribunal Europeo de Derechos Humanos encontramos algunos elementos de contraste significativos.

Especialmente, la Carta Magna de los Jueces Europeos, aprobada en 2010²1, el informe de Grupo de Estados contra la Corrupción (GRECO) sobre el cumplimiento de sus recomendaciones ${ }^{22}$, los resultados del EU Justice Scoreboard ${ }^{23}$ y la sentencia dictada por el Tribunal de Estrasburgo en el asunto Ramos Nunes de Carvalho e Sá contra Portugal el 21 de junio de 2016 24 .

La primera, propugna que, para garantizar la independencia judicial, los Consejos de la Magistratura estén compuestos en exclusiva o por una mayoría de jueces y que éstos sean elegidos por sus pares. GRECO considera que España no ha cumplido las recomendaciones para evitar toda duda sobre la independencia e imparcialidad de los jueces y los resultados del EU Justice Scoreboard reflejan una baja percepción de la independencia judicial en España.

Por su parte, la sentencia, sumamente importante para el asunto que estoy abordando, se ocupa, entre otros extremos, de la composición que deben tener los consejos de la magistratura para garantizar la independencia judicial. Y lo importante es que, si bien toma nota de cuanto afirman los documentos internacionales mencionados y otros, no dice que los miembros judiciales de estos órganos deban ser elegidos por sus pares. Es decir, no concluye que lo exija el artículo 6 del Convenio Europeo para la salvaguardia de los derechos humanos y las libertades fundamentales.

\section{LA INDEPENDENCIA Y LA SUMISIÓN A LA LEY DE LOS JUECES ESPAÑOLES}

El juez tiene que ser independiente pero ¿frente a quién?

Según Montesquieu, siendo el juez la boca que pronuncia las palabras de la ley, su poder es en cierto modo nulo.

21 Puede verse en www.coe.int/ccje.

22 Véase en http://www.coe.int/en/web/greco/evaluations/spain.

23 El EU Justice Scoreboard es una herramienta destinada a asistir a la Unión Europea y a los Estados miembros que la componen en su propósito de conseguir una justicia más efectiva suministrándoles datos objetivos, fiables y comparables sobre la calidad de los sistemas judiciales nacionales. Cfr. http://ec.europa.eu/ justice/effective-justice/scoreboard/index_en.htm.

24 Recursos no $55391 / 13,57728 / 13$ y $74041 / 13$. 
La realidad demuestra todo lo contrario. El poder de los jueces es de primera magnitud pues decide sobre la libertad, sobre la vida personal y familiar y sobre el patrimonio de individuos y sociedades. Además, limita efectivamente la acción de los gobernantes y les exige su responsabilidad.

Es, por tanto, natural que tal capacidad no pase desapercibida. El poder de los jueces llama, atrae a los otros poderes, sean públicos o privados, y se hace imprescindible resguardarlos de la inevitable tendencia de estos a injerirse en su ámbito no sólo para evitar que se produzca esa injerencia sino, también, para eliminar, incluso, la apariencia de que puede producirse.

Llegados a este punto es menester preguntarnos qué sucede en España.

Hasta ahora nadie ha podido acreditar que los jueces carezcan de la independencia que deben poseer.

Sin embargo, a tenor de lo expresado por las entidades a las que me he referido, sucedería todo lo contrario.

Igualmente, autores de prestigio ${ }^{25}$ han expresado juicios de tremenda dureza o sugieren ya en el título de sus obras la existencia de problemas graves para la independencia judicial, en particular de la que se llama «cúpula judicial», mientras que absuelven del sometimiento a la clase política, al que sí se prestaría esa «alta judicatura», a los demás jueces ${ }^{26}$.

Me parecen más ajustadas a la realidad las observaciones que ponen de manifiesto que la independencia judicial es un principio en tensión ${ }^{27}$ que exige, ante todo, el compromiso del propio juez y que puede resultar condicionada por múltiples factores. Y que, pese a las dificultades que le salen al camino, no se puede negar que los jueces tienen todos un estatuto de independencia en España, razonablemente garantizado por el marco legal y en la práctica ${ }^{28}$.

$\mathrm{Al}$ margen de su integridad personal — que, debiendo presumirse, muchas veces parece ignorarse o, simplemente, se da por supuesta su ausencia- no se hallan objetivamente en situación de ser condicionados ni, mucho menos, sometidos por las presiones de los gobernantes.

¿Por qué, entonces, está difundida la idea de que los jueces españoles no son independientes? ${ }^{29}$

Se suele acompañar la afirmación de que son todos y cada uno personalmente independientes, con la de que el sistema no asegura la independencia. E inmediatamente se relaciona con otro hecho que se da por demostrado: la politización de

25 Me refiero ahora a los libros de NieTo, A; El desgobierno judicial, $3^{\mathrm{a}}$ ed. Trotta/Fundación Alfonso Martín Escudero, Madrid, 2005, y El malestar de los jueces y el modelo judicial, cit., págs. 114 y sigs.

26 Es el caso de SOSA WAGNER, F; La independencia del juez. ¿Una fábula? Un relato escrito para personas curiosas y legas. La esfera de los libros, Madrid, 2016.

27 Como hace ANDrés IbÁÑEZ, P; El tercero en discordia. Jurisdicción y Juez en el Estado Constitucional. Trotta, Madrid, 2015, págs., 139 y sigs. y 163 y sigs.

28 ANDRÉs IBÁÑEZ, P; op. cit. pág. 156.

29 Por ejemplo, la reflejan los EU Justice Scoreboard 2015, 2016 y 2017. 
la justicia. A su vez, este fenómeno patológico se vincula con el permanente debate sobre la elección de los vocales judiciales y con las disputas que se producen en el seno del Consejo, especialmente con motivo de algunos de los nombramientos discrecionales. Según la crítica más extrema, esos nombramientos estarían sometidos a la voluntad de los partidos políticos que mediatizan a los vocales respectivos, a los que han elegido, y logran que orienten en el sentido que aquellos desean los nombramientos.

La conclusión es la de que los nombrados discrecionalmente no serían independientes ni imparciales y, en la medida en que actuarían al servicio de los designios de quienes les nombraron, tampoco ejercerían la potestad jurisdiccional con sumisión a la ley. Y, por fuerza, habría que concluir que, de ser todo ello cierto, no estaríamos ya ante el mero incumplimiento de la Constitución sino ante un fenómeno infinitamente más grave.

Creo que los hechos no permiten descripciones e interpretaciones de tal naturaleza. Ni se conocen intentos groseros de atentar contra la independencia judicial desde los poderes públicos, ni puede considerarse que cumplir a conciencia con la responsabilidad que implica la potestad jurisdiccional, exponga a los jueces a sanciones ni que les cierre el camino a los ascensos.

Cierto, el Consejo exige la responsabilidad disciplinaria en que incurren los miembros de la carrera judicial pero sólo puede hacerlo en virtud de un expediente que debe resolverse en un tiempo determinado y cuenta con todas las garantías. Expediente que sólo podrá incoarse cuando haya indicios de la comisión de alguna de las infracciones tipificadas y únicamente podrá conducir a una de las sanciones igualmente previstas cuando se prueben los hechos y la culpabilidad del expedientado, al que nunca se le podrán imputar los defectos derivados de las carencias del órgano judicial.

Por otro lado, la inmensa mayoría de los destinos judiciales se logra por concurso y para obtener mejor posición en él las claves, además de en la antigüedad, están en la especialización. Esto significa que a los juzgados de las capitales, a las Audiencias Provinciales, a los Tribunales Superiores de Justicia y a la Audiencia Nacional se llega por concursos sometidos a criterios esencialmente objetivos.

Es verdad que el acceso a las presidencias de tribunales y de salas y al Tribunal Supremo se produce por nombramiento discrecional. Se trata de algo menos de dos centenares de puestos aunque sumamente cualificados ${ }^{30}$. De ahí el eco que alcanza la controversia — y su efecto negativo— cuando la elección es discutida.

30 Según las previsiones actualizadas de la Ley 38/1988, de 28 de diciembre, de Demarcación y Planta, son setenta y nueve plazas de magistrados del Tribunal Supremo, cinco de ellos presidentes de Sala, además de su Presidente y Vicepresidente; el Presidente de la Audiencia Nacional y los presidentes de sus tres Salas; los diecisiete Presidentes del Tribunales Superiores de Justicia y los presidentes de sus Salas de lo Contencioso Administrativo y de lo Social (en Andalucía hay tres de cada uno de esos dos órdenes; en Canarias, dos y en Castilla y León otras dos); y los cincuenta presidentes de Audiencias Provinciales. En www.poderjudicial.es se pueden ver los anexos a la Ley en que se detallan las plazas. 
No obstante, la jurisprudencia, las normas que la han recogido y la vigilancia de la opinión pública han limitado notablemente el margen del Consejo. Por tanto, el mantenimiento de posiciones críticas no se traduce en la imposibilidad de ser nombrado, ni la coincidencia con la orientacion del Consejo o la proximidad a quienes lo componen lo asegura.

Todo está dispuesto para que todos los jueces sean independientes e imparciales, siempre que quieran serlo, que es lo que pretenden, si no absolutamente todos, sí la inmensa mayoría del mismo modo que sucede con quienes integran cualquier otro cuerpo, profesión u oficio.

¿Cuál es, entonces, la razón por la que se produce esa separación entre la imagen que reflejan los sondeos y cuanto acabo de decir?

En gran medida depende de la percepción que se transmite a través de los medios y de la dificultad para distinguir el órgano de gobierno del Poder Judicial y los tribunales. Muy a menudo, con la palabra justicia se abarca todo, al Consejo, a los jueces, a los fiscales y a la Administración de Justicia. Incluso se incluye al Tribunal Constitucional. En esa agregación de elementos heterogéneos, es fácil que se trasladen al conjunto juicios que se refieren solamente a una de sus partes.

Sin duda los enfrentamientos vividos en el seno del Consejo han acabado proyectando sobre todos los jueces la sombra de la división política en el quehacer judicial ${ }^{31}$.

A la creación en amplios sectores de la opinión de una imagen dependiente o condicionada del Poder Judicial han contribuido, además, los propios actores políticos. Han observado escaso cuidado a la hora de ponerse de acuerdo sobre los candidatos a formar parte del Consejo y se ha llegado, incluso, a producir la elección parlamentaria para vocal de quien veía cernirse sobre él un proceso penal que acabaría en su condena por el Tribunal Supremo ${ }^{32}$.

$Y$ ha ayudado a ese efecto generalizador de la opinión negativa otro proceder de los mismos contendientes políticos: recurrir a los procesos judiciales, principalmente penales y contencioso-administrativos, para combatir a sus adversarios. Mal uso de la Constitución denunciado por uno de sus ponentes, Miguel Herrero y Rodríguez de Miñón ${ }^{33}$.

31 Entre las numerosas opiniones críticas, destaca la de Í̃̃IGUEZ HERNÁNDEZ, D; El fracaso del autogobierno judicial, cit, por el completo y riguroso examen que hace de la trayectoria del Consejo General del Poder Judicial. Véase, también, LuCAS Murillo de la Cueva, P; «La posición constitucional del Consejo General del Poder Judicial y sus relaciones con los órganos constitucionales», en Gerpe Landín, M; y Cabellos EsPiÉrrez, M.A; El gobierno del Poder Judicial en el Estado Autonómico. Evolución y perspectivas de reforma, cit. págs., 47 y sigs.

32 Véanse las sentencias de la Sala Segunda del Tribunal Supremo n 1 , de 4 de julio de 1996 (causa especial 2830/1994) y la no 842, de 31 de julio de 2006 (casación 409/2005).

33 Herrero y Rodríguez de Miñón, M; «Malos y buenos usos de la Constitución», en Anales de la Real Academia de Ciencias Morales y Políticas, n 81-1/2004, pág. 69, incluye entre los buenos usos que reclama corregir el defecto que detecta consistente en judicializar la contienda política, «remitiendo a la decisión de los jueces e, incluso, del Tribunal Constitucional, lo que los políticos no han sabido resolver o (...) se han empeñado en enconar». Corrección que, observa, «no se consigue haciendo de la administración de justicia 
De ahí que sea esencial insistir en que tal traslación no es coherente con la respectiva posición del órgano de gobierno y de los tribunales. Y subrayar que estos no se implican en las diferencias que surgen en el seno del Consejo.

Superar esa confusión requerirá de pedagogía y la mejor que puede ofrecerse es la de extremar la prudencia en las propias actuaciones tanto por parte los llamados a gobernar el Poder Judicial cuanto por parte de quienes hayan de elegir a los miembros del Consejo y, en general, deban mantener con él las relaciones que el ordenamiento constitucional prevé.

\section{LA INDEPENDENCIA JUDICIAL Y LA OPINIÓN PÚBLICA}

Los condicionamientos más complejos a los que está sujeto hoy el ejercicio de la función jurisdiccional son los que resultan de la posible trascendencia social de un determinado asunto ${ }^{34}$.

Los jueces están suficientemente protegidos frente a las eventuales tentaciones de los legisladores o de los gobernantes de influir en su actuación. También están al abrigo de eventuales excesos de los órganos de gobierno del Poder Judicial.

Tampoco de las partes en el proceso pueden provenir especiales problemas.

En cambio, ante las opiniones vertidas en los medios que, con frecuencia, adjudican a los jueces etiquetas ideológicas cuando no partidistas e, incluso, anticipan en función de ellas sus decisiones en asuntos notorios, el juez no tiene más que su propio criterio para hacerlas frente.

Y ha de ser capaz no sólo de ser independiente sino también de parecer que lo es.

En ese ámbito, en el que juega un papel esencial la capacidad dialéctica, la facilidad de comunicación, la agilidad en la respuesta, la simplificación de los mensajes, el juez no está en condiciones de ofrecer las réplicas necesarias. Ni para satisfacer las demandas de información ni para contrarrestar posibles imágenes inexactas, deformadas o, simplemente, inciertas que de él o de su actuación se hayan difundido. El juez que, como ciudadano, es titular de todos los derechos fundamentales, no puede entablar un debate público sobre los asuntos de los que está conociendo. No se halla en igualdad de armas, pues ni puede hacer público lo que conoce por el ejercicio de su cargo, ni puede discutir con plena libertad so pena de perder la imparcialidad que en todo momento ha de mantener.

Desde luego, el juez que se vea inmerso en un episodio de trascendencia mediática en el que se cuestione su actuación puede acudir al Consejo si considera

\footnotetext{
una «rueda suelta» del gran aparato que es el Estado, ajena a su razón, a la que, sin embargo se trata permanentemente de influir, sino dialogando respetuosa y constantemente».

34 Sigo aquí las consideraciones que ya expuse en mis respuestas a la Encuesta sobre la independencia del Poder Judicial, publicada en el número 38/2016 de esta revista, en particular en las págs. 26 a 28.
} 
perturbada su independencia y solicitar su amparo ${ }^{35}$. Y el Consejo lo ha concedido en algunos casos. Pero son pocas las ocasiones en que los jueces hacen uso de este remedio. Su utilidad está directamente relacionada con la autoridad de la que disponga el Consejo. Si es discutida, el apoyo que puede prestar pierde buena parte de su virtualidad si no toda.

El artículo $124 \mathrm{CE}$ encomienda al Ministerio Fiscal «velar por la independencia de los Tribunales» pero esta previsión se sitúa en un plano diferente, el del proceso. El Ministerio Fiscal no está para explicar a los ciudadanos que la actuación del juez que concita la crítica pública se ha ajustado a los requerimientos legales.

Las asociaciones judiciales pueden salir al paso de las descalificaciones de decisiones judiciales, sobre todo, si el juez afectado es miembro de una de ellas, pero su carácter corporativo priva de la dimensión institucional necesaria a sus manifestaciones.

El sometimiento al escrutinio público es, en todo caso, una condición inherente al ejercicio de la función jurisdiccional y a la publicidad del proceso judicial. Forma parte de la responsabilidad, si bien difusa, que corresponde a quienes son titulares de poderes públicos. De ahí que los jueces experimentados hayan desarrollado los mecanismos para hacer frente al exceso de exposición mediática e, incluso, a las especulaciones sobre sus preferencias y decisiones, si es que se ven en esas circunstancias.

A tal efecto cumple un papel esencial la motivación de las resoluciones judiciales.

Cuanto mejor y más claramente se expliquen menos deberán preocuparse quienes las firman por las opiniones que sobre ellos se formen en los espacios públicos.

A partir de aquí, hay que aceptar que los jueces pueden equivocarse y, de hecho, se equivocan. Y que tienen sus convicciones ideológicas y sus preferencias políticas, como cualquier otra persona normal aunque no pueden dejarse llevar por ellas al ejercer la jurisdicción y, para preservar su imagen de independencia e imparcialidad, más allá de la observancia de los deberes y prohibiciones legales, deben ser especialmente prudentes en sus manifestaciones públicas para evitar la apariencia contraria que, de otro modo, podría crearse.

Pero, en conclusión, insisto, los jueces españoles son independientes.

\section{HACIA UNAS CONCLUSIONES SOBRE EL GOBIERNO DEL PODER JUDICIAL}

¿Qué cabe decir de su órgano de gobierno? ¿Ha de buscársele una alternativa?

35 Sobre el remedio ofrecido por el artículo 14 de la Ley Orgánica del Poder Judicial, véase MARTínEZ Alarcón, Ma . L; La independencia judicial. Centro de Estudios Políticos y Constitucionales, Madrid 2004, págs. 308 y sigs. 
La respuesta tiene que ser negativa, precisamente porque los jueces españoles son independientes. Algo habrá tenido que ver con ello el Consejo. Con todos los defectos, insuficiencias y errores en que pueda haber incurrido no ha impedido que los jueces españoles ejerzan sin cortapisas la función jurisdiccional. Justamente, por eso, no tendrían fácil justificación las propuestas que defendieran devolver al Ministerio de Justicia todas o parte de las tareas desempeñadas por el Consejo o crear otras instancias para sustituirlo.

Sin embargo, existen, los hemos visto, problemas serios.

Por tanto, algo se ha de hacer.

La solución no puede consistir en retocar las instituciones hasta desfigurar la imagen que de ellas ofrece la Constitución.

El posible desacierto de algunas regulaciones constitucionales no implica una autorización para sortearlas por la vía legislativa. Debe conducir a su reforma. La Constitución la permite y es posible realizarla sin grandes complicaciones cuando existe el acuerdo político necesario.

Por ejemplo, para superar situaciones de bloqueo político en la formación de los órganos constitucionales de garantía. No obstante, se ha optado por imputar el retraso en el acuerdo parlamentario a la duración del cargo de quien finalmente es nombrado a pesar de que la Constitución establece que los nombramientos son por un período determinado que ya no se cumple ${ }^{36}$.

Y deberíamos haber aprendido que la alteración legal de las estructuras del Consejo no es la mejor forma de afrontar sus problemas. Si, como parece, se ha llegado a la conclusión de que son excesivos veinte vocales, pueden reducirse a un número menor. No debe ser difícil coincidir en el necesario y llevarlo a la Constitución en vez de establecer diferencias entre ellos que no aparecen en el texto fundamental.

También conviene reflexionar sobre el peso que han de tener las razones de eficacia a la hora de fijar las reglas sobre el quorum y las mayorías necesarias para decidir frente a las ventajas de un amplio acuerdo en el gobierno del Poder Judicial.

En fin, el problema de la elección de los vocales, de todos ellos, tiene una solución clara.

Reparemos en que la Constitución quiere que los ocho vocales no judiciales sean elegidos entre juristas de reconocida competencia —es el único criterio cualitativo que nos da- con más de quince años de ejercicio. Y que la elección sea por mayoría de tres quintos para que no haya imposiciones de parte. La exigencia de que los otros doce vocales sean jueces en activo refuerza el perfil técnico querido por los constituyentes. Son motivos suficientes para saber que los autores de la Constitución quisieron que para este órgano se elija a quien posea prestigio

36 A esta cuestión me referí en «Las mayorías reforzadas y la formación de los órganos constitucionales (Comentarios sobre la actualidad)», en Parlamento y Constitución. Anuario, nº 13/2010, págs. 123 y sigs. 
profesional y se le reconozca criterio propio y resolución para mantenerlo. Aquí está la clave.

El problema no es el reparto de cuotas sino el que busca partidarios o se hace desentendiéndose cada uno de a quién propone el otro con tal de que acepte al propio. O sea, la lógica de las cuotas ciegas.

En consecuencia, el factor humano se revela decisivo ${ }^{37}$. Una buena elección contribuye a hacer buenas, incluso, instituciones deficientemente diseñadas, pero una elección desacertada consigue destruir hasta las mejor ideadas.

La elección de todos los vocales la deben hacer las Cortes. Si se combina, en el caso de los de origen judicial, con formas de propuesta o aval de los jueces, mejor. Pero deben ser las Cortes, que representan al pueblo español del que emana la Justicia, quienes decidan. Con todo el respeto que merece un cuerpo de servidores públicos como la carrera judicial y las asociaciones profesionales que encuadran a la mitad de sus miembros, no me parece que estén legitimados para reclamar la facultad de elegir a la mayor parte de los integrantes de un órgano constitucional.

Soy consciente de que la postura que mantengo tiene en contra a las asociaciones judiciales y a otros colectivos importantes y que las recomendaciones del Consejo de Europa van en sentido contrario.

Prefiero, no obstante, recordar la prudencia del Tribunal Europeo de Derechos Humanos en este punto y la real independencia de nuestros jueces. También creo que la designación parlamentaria enlaza con la esencia de las ideas de separación de poderes y de limitación del poder. No sólo propugnan separarlos sino también establecer frenos y contrapesos que favorezcan el equilibrio entre ellos. Desde esa perspectiva no es incoherente, sino todo lo contrario, compensar la mayoria que se entrega a los jueces en el órgano que ha de administrar su estatuto, con el contrapeso que supone la designación parlamentaria por consenso de quienes han de integrarlo.

\section{CONSIDERACIÓN FINAL}

La superación de la ya larga polémica en torno al Consejo y de las consecuencias deslegitimadoras que ha supuesto no pasa necesariamente, salvo en el aspecto de su tamaño, por la reforma de la Constitución.

Es un problema esencialmente político que afecta a los equilibrios de poder y, como tal, debe recibir una solución política que sólo puede provenir del consenso $^{38}$, de la consecución de una convención constitucional que, por fin,

37 A él se refiere ÍñIgUEZ, El fracaso del autogobierno judicial, cit. págs. 504 y sigs., como una de las claves para le regeneración del Consejo General del Poder Judicial.

38 Véase la defensa del acuerdo constituyente que hace Alzaga Villaamil, O; en Del consenso constituyente al conflicto permanente. Editorial Trotta. Fundación Alfonso Martín Escudero. Madrid, 2011. 
neutralice políticamente la formación de los órganos constitucionales de garantía $y$, en general, asiente una cultura de respeto institucional.

En tiempos de crisis, de cuestionamiento de las instituciones e, incluso, de propuesta de un proceso constituyente, es imprescindible reconstruir los elementos que unen a quienes mantienen posiciones distintas pero coinciden en lo principal. Lo exige la empresa de regenerar el Estado social y democrático de Derecho y restaurar el sentimiento constitucional, ese vínculo moral que une a los ciudadanos con las instituciones mediante las que se gobiernan ${ }^{39}$.

$$
* * *
$$

TITLE: The Independence and Government of the Judiciary. A constitutional debate.

ABSTRACT: Although not perceived by a great part of the public opinion, the text affirms the independence of the Spanish Judges. Also defends the General Council of the Judiciary but maintains that their members must be elected by the Cortes among judges and jurists of acknowledged competence and proven ability for sustaining their own criteria.

Resumen: El artículo defiende la independencia de los jueces españoles aunque buena parte de la opinión pública no la perciba. También aboga por el mantenimiento del Consejo General del Poder Judicial si bien considera necesario que en la elección de todos los vocales por las Cortes se observe la exigencia constitucional de que recaiga en jueces y juristas de reconocida competencia y demostrada capacidad de mantener su criterio.

KEY WORDS: Independence and Government of the Judiciary, Constitution.

Palabras Clave: Independencia y Gobierno de los Jueces, Constitución.

FECHA DE RECEPCIÓN: 12.05.2017 FeCHA DE ACEPTACIÓN: 26.07.2017

39 Sobre ello, véase LuCAs VERdú, P; El sentimiento constitucional. Editorial Reus, Madrid, 1985. 